\title{
An outbreak of Ralstonia pickettii endophthalmitis following intravitreal methotrexate injection
}

This article was published in the following Dove Press journal:

Clinical Ophthalmology

23 June 2015

Number of times this article has been viewed

\author{
Himadri Choudhury' \\ Animesh Jindal' \\ Avinash Pathengay' \\ Harry W Flynn Jr2 \\ 'LV Prasad Eye Institute, GMR \\ Varalakshmi Campus, Visakhapatnam, \\ India; ${ }^{2}$ Department of Ophthalmology, \\ Bascom Palmer Eye Institute, Miller \\ School of Medicine, University of \\ Miami, Miami, FL, USA
}

Purpose: To report an outbreak of endophthalmitis in three eyes of two patients following intravitreal methotrexate, caused by Ralstonia pickettii.

Design: Retrospective, noncomparative, consecutive case series.

Methods: Medical records and microbiology results of two patients who presented with acute endophthalmitis following intravitreal methotrexate injection in November 2013 were reviewed.

Results: Following intravitreal injections, the patients experienced pain and decrease in vision in the affected eye within 24 hours of receiving intravitreal methotrexate injection. The presenting visual acuity in case 1 was 20/50 in the left eye. The presenting visual acuity in case 2 was hand motions in the right eye and counting fingers at $1 \mathrm{~m}$ in the left eye. Both the patients received methotrexate prepared in the same manufacturing facility. Both the patients underwent vitreous biopsy and intravitreal injection of vancomycin $1 \mathrm{mg} / 0.1 \mathrm{~mL}$, amikacin $400 \mu \mathrm{g} / 0.1 \mathrm{~mL}$, and dexamethasone $400 \mu \mathrm{g} / 0.1 \mathrm{~mL}$. Microbiology cultures from vitreous, and used and unused vials of methotrexate from the same batch grew $R$. pickettii. After 8 months of follow-up, both the patients had visual acuity $20 / 60$ or better.

Conclusion: $R$. pickettii can be rarely associated with outbreak of endophthalmitis. Timely intervention can be associated with good visual outcome in such patients.

Keywords: Ralstonia pickettii, intravitreal injection, intravitreal methotrexate

\section{Introduction}

Intravitreal methotrexate was first used in the treatment of primary intraocular lymphoma. ${ }^{1}$ Over the years, it has been used to treat posterior and intermediate uveitis. ${ }^{2-4}$ Methotrexate injected directly into the vitreous cavity is generally well tolerated and has very few complications. The incidence of endophthalmitis, following intravitreal injections ranges from $0.02 \%$ to $0.05 \%{ }^{5,6}$ Most reports have described endophthalmitis following intravitreal injections of anti-VEGFs or long-acting corticosteroids. ${ }^{7,8} \mathrm{We}$ report two cases of endophthalmitis following intravitreal injection with methotrexate contaminated by Ralstonia pickettii. Although Ralstonia species are considered to be a rare infectious organism, recent reports suggest that the organism may be more virulent and widespread than previously thought and may cause infections ranging from asymptomatic colonization to septicemia and death. ${ }^{9}$

\section{Methods}

The current study is a retrospective, noncomparative, consecutive case series. Informed consent was obtained prior to intraocular injections. Intraocular injections were done in the operating room under topical anesthesia and prophylactic povidone-iodine eye drops were used pre- and postinjections. Separate sterile drape, speculum, topical 
anesthetic drops, povidone-iodine preparation, syringe, and needle were used for each eye. All eyes received intravitreal injections from different vials. Vitreous biopsy was done to obtain the vitreous sample. The age, sex, the affected eye, lens status, the date of the most recent injection, the underlying diagnosis, clinical indication for intravitreal injection, the preinjection visual acuity, the presenting symptoms and signs, management, as well as the microbiology result and postinjection visual acuity were documented.

\section{Results}

\section{Case report I}

A 28-year-old male presented with pain, redness, and diminution of vision in the left eye 24 hours after intravitreal methotrexate injection for idiopathic retinal vasculitis. On examination, his best-corrected visual acuity (BCVA) in the left eye was 20/50. His preinjection BCVA had been recorded as $20 / 30$. The conjunctiva was congested with $4+$ cells in the anterior chamber and a $2 \%$ hypopyon. ${ }^{10}$ The view to the posterior segment was hazy, with a media clarity of grade $2 .{ }^{11}$ He was diagnosed with acute-onset endophthalmitis and underwent vitreous biopsy and injection of intravitreal vancomycin $1 \mathrm{mg} / 0.1 \mathrm{~mL}$, amikacin $400 \mu \mathrm{g} / 0.1 \mathrm{~mL}$, and dexamethasone $400 \mu \mathrm{g} / 0.1 \mathrm{~mL}$. The patient was started on oral ciprofloxacin along with oral and topical corticosteroids. The visual acuity started improving within 1 week, and the patient had a BCVA of 20/50 after 8 months of follow-up.

\section{Case report 2}

A 46-year-old male patient presented with diminution of vision, pain, and watering in both the eyes 6 hours after intravitreal methotrexate injection for pars planitis with cystoid macular edema. On examination, his BCVA was hand motions in the right eye and counting fingers at $1 \mathrm{~m}$ in the left eye. Preinjection visual acuity had been recorded as 20/20 in both eyes. Both the eyes had conjunctival congestion with $3-4+$ cells in the anterior chamber and a 5\% hypopyon. ${ }^{10}$ On fundus evaluation, the disc could be hazily seen with a media clarity of grade $3 .{ }^{11}$ He was diagnosed with acute-onset endophthalmitis. The patient underwent vitreous biopsy and injection of intravitreal vancomycin $1 \mathrm{mg} / 0.1 \mathrm{~mL}$, amikacin $400 \mu \mathrm{g} / 0.1 \mathrm{~mL}$, and dexamethasone $400 \mu \mathrm{g} / 0.1 \mathrm{~mL}$ in both eyes and received oral ciprofloxacin and oral corticosteroids along with frequent topical corticosteroids (Figure 1A). The visual acuity started improving within 1 week (Figure 1B), and at last follow-up visit 8 months later, the patient had a BCVA of 20/60 in right eye and 20/50 in the left eye.

The patients presented with diminution of vision along with pain within 24 hours of injection. The vitreous samples of the patients along with the used vials of methotrexate and two unused vials from the same batch were sent for culture and sensitivity. Microbiology cultures from both vitreous samples, and used and unused vials of methotrexate from the same batch grew $R$. pickettii. The sensitivities were detected using the Kirby-Bauer disc diffusion method. Microbiological identification was done using the Vitek 2 system (bioMérieux Inc, Marcy l'Etoile, France). Each of the isolates was susceptible to ciprofloxacin, amikacin, imipenem, moxifloxacin and was resistant to ceftazidime, chloramphenicol, and gentamicin. Both these patients were not able to tolerate systemic methotrexate and hence were injected with intravitreal methotrexate. Following the resolution of infection, clearance of hypopyon and intraocular inflammation occurred.
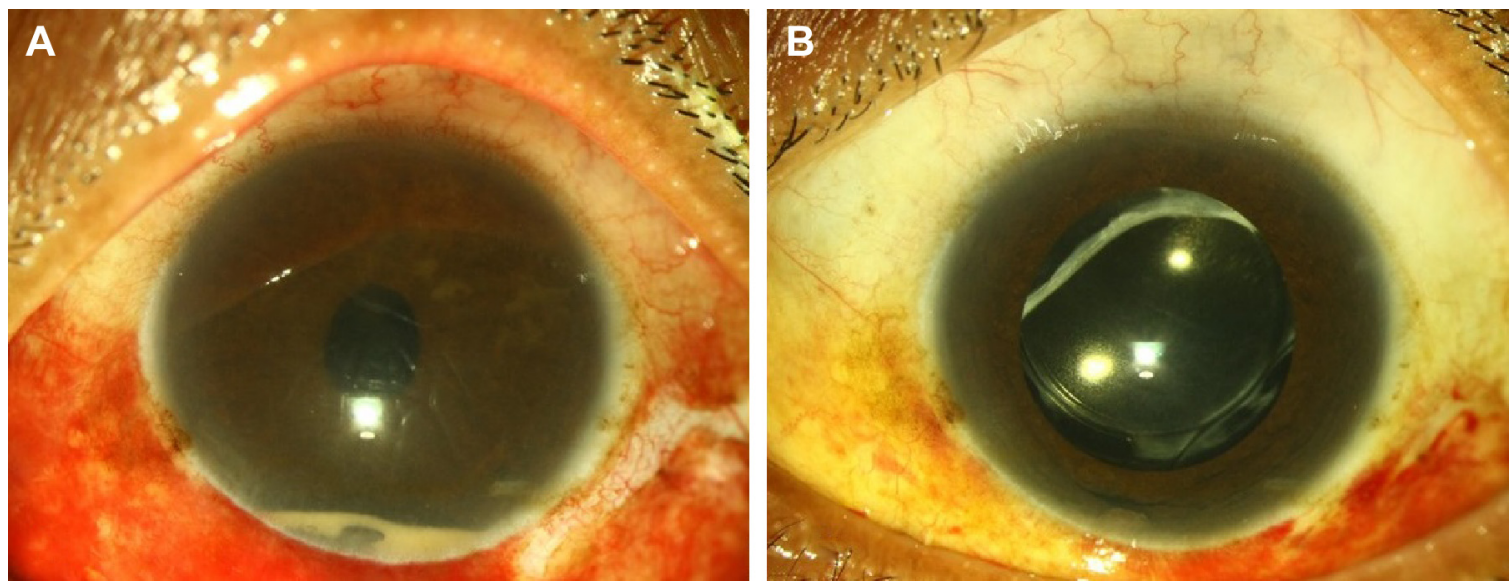

Figure I Clinical photograph of the left eye of case 2.

Notes: (A) Clinical photograph at I day post vitreous biopsy + intraocular antibiotic injection showing persistent hypopyon and (B) at I week follow-up showing resolution of hypopyon. 
Table I Demographic profile, clinical features, and the results of treatment of the patients diagnosed with endophthalmitis caused by Ralstonia Pickettii

\begin{tabular}{|c|c|c|c|c|c|c|c|c|}
\hline Case & Age/sex & Eye & $\begin{array}{l}\text { Preinjection } \\
\text { visual acuity }\end{array}$ & $\begin{array}{l}\text { Visual acuity at } \\
\text { presentation }\end{array}$ & $\begin{array}{l}\text { Anterior chamber } \\
\text { reaction }{ }^{10}\end{array}$ & Media haze"I & Intervention & $\begin{array}{l}\text { Final visual } \\
\text { acuity }\end{array}$ \\
\hline I & 28 years $/ M$ & OS & $20 / 30$ & $20 / 50$ & 4+, Hypopyon & Grade 2 & $\begin{array}{l}\text { Vitreous biopsy }+ \\
\text { intraocular antibiotic }\end{array}$ & $20 / 50$ \\
\hline \multirow[t]{2}{*}{2} & 46 years $/ M$ & OD & $20 / 20$ & Hand motions & 4+, Hypopyon & Grade 3 & $\begin{array}{l}\text { Vitreous biopsy }+ \\
\text { intraocular antibiotic }\end{array}$ & $20 / 60$ \\
\hline & & OS & $20 / 20$ & $\begin{array}{l}\text { Counting fingers } \\
\text { at I meter }\end{array}$ & 4+, Hypopyon & Grade 3 & $\begin{array}{l}\text { Vitreous biopsy }+ \\
\text { intraocular antibiotic }\end{array}$ & $20 / 50$ \\
\hline
\end{tabular}

Abbreviations: OS, left eye; OD, right eye; M, male.

The profile of the patients, clinical features, and the result of treatment are summarized in Table 1.

\section{Discussion}

Endophthalmitis outbreaks following intravitreal injections, although rare, have been reported all over the world. ${ }^{12}$ Most of these outbreaks were caused by drug contamination at the compounding pharmacies or even spurious drugs, and majority of the culture-positive cases involved Staphylococcus and Streptococcus species. ${ }^{13,14}$

R. pickettii previously known as Burkholderia pickettii or Pseudomonas pickettii is a nonfermenting Gram-negative bacillus and an opportunistic pathogen in both the hospital setting and from environmental sources. ${ }^{15}$ It has been isolated from multiple clinical specimens including blood, urine, and cerebrospinal fluid. ${ }^{16} \mathrm{~A}$ wide variety of infections ranging from minor skin infections to septicemia may be caused by this organism. Most of the cases of infection with R. pickettii have been attributed to contaminated solutions, including water for injection, saline solutions made with purified water, and sterile drug solutions. ${ }^{17-20}$ Contamination of the product usually happens at the manufacturing stage and may be due to the ability of $R$. pickettii to pass through both $0.45-\mathrm{mm}$ and $0.2-\mathrm{mm}$ filters that are used for the terminal sterilization of several medicinal products. ${ }^{21}$ The organism can also form a biofilm and can survive hospital disinfectants like chlorhexidine and ethacridine lactate..$^{22,23}$

In the current study, the infection could be traced to the contaminated vials of methotrexate. The vials were of the same batch and had been manufactured at the same facility where the breach in sterility may have occurred. The cultured isolates from each of the vials and vitreous had similar antibiotic susceptibility patterns. The isolates were resistant to ceftazidime, a third-generation cephalosporin which is commonly used for empirical therapy in endophthalmitis. Resistance to $\beta$-lactam antibiotics is most commonly due to production of $\beta$-lactatamase, which leads to the enzymatic deactivation of the drug. It has been reported previously that Ralstonia may produce a variety of $\beta$-lactamases, including ceftazidime and imipenem, hydrolyzing OXA-60. ${ }^{24}$ This can have implications in the treatment of Ralstonia-associated endophthalmitis. Polymerase chain reaction (PCR) may also be helpful in identifying organisms like Ralstonia, which are not commonly implicated in postoperative endophthalmitis. ${ }^{25}$ Good clinical outcome has been reported before in patients with PCR-proven $R$. pickettii endohthalmitis, with intravitreal ceftazidime. ${ }^{25}$ This indicates that all isolates may not be ceftazidime resistant.

\section{Conclusion}

R. pickettii is an important pathogen that may cause an outbreak of endophthalmitis. Prompt and early intervention in such outbreaks can be associated with favorable visual outcomes.

\section{Disclosure}

The authors report no conflicts of interest in this work.

\section{References}

1. Fishburne BC, Wilson DJ, Rosenbaum JT, Neuwelt EA. Intravitreal methotrexate as an adjunctive treatment of intraocular lymphoma. Arch Ophthalmol. 1997;115(9):1152-1156.

2. Taylor SR, Habot-Wilner Z, Pacheco P, Lightman SL. Intraocular methotrexate in the treatment of uveitis and uveitic cystoid macular edema. Ophthalmology. 2009;116(4):797-801.

3. Bae JH, Lee SC. Effect of intravitreal methotrexate and aqueous humor cytokine levels in refractory retinal vasculitis in Behçet disease. Retina. 2012;32(7):1395-1402.

4. Taylor SR, Banker A, Schlaen A, et al. Intraocular methotrexate can induce extended remission in some patients in noninfectious uveitis. Retina. 2013;33(10):2149-2154.

5. McCannel CA. Meta-analysis of endophthalmitis following intravitreal injection of anti-VEGF agents: causative organisms and possible prevention strategies. Retina. 2011;31(4):654-661.

6. Moshfeghi AA, Rosenfeld PJ, Flynn HW Jr, et al. Endophthalmitis after intravitreal anti-vascular endothelial growth factor antagonists: a six-year experience at a university referral center. Retina. 2011;31(4): 662-668.

7. Englander M, Chen TC, Paschalis EI, Miller JW, Kim IK. Intravitreal injections at the Massachusetts Eye and Ear Infirmary: analysis of treatment indications and postinjection endophthalmitis rates. $\mathrm{Br} J$ Ophthalmol. 2013;97(4):460-465. 
8. Bhavsar AR, Ip MS, Glassman AR; DRCRnet and the SCORE Study Groups. The risk of endophthalmitis following intravitreal triamcinolone injection in the DRCRnet and SCORE clinical trials. Am J Ophthalmol. 2007;144(3):454-456.

9. Orme J, Rivera-Bonilla T, Loli A, Blattman NN. Native valve endocarditis due to Ralstonia pickettii: a case report and literature review. Case Rep Infect Dis. 2015;2015:324675.

10. Jabs DA, Nussenblatt RB, Rosenbaum JT, et al. Standardization of uveitis nomenclature for reporting clinical data. Results of the First International Workshop. Am J Ophthalmol. 2005;140:509-516.

11. Nussenblatt RB, Palestine AG, Chan CC, Roberge F. Standardization of vitreal inflammatory activity in intermediate and posterior uveitis. Ophthalmology. 1985;92(4):467-471.

12. Goldberg RA, Flynn HW Jr, Isom RF, Miller D, Gonzalez S. An outbreak of streptococcus endophthalmitis after intravitreal injection of bevacizumab. Am J Ophthalmol. 2012;153(2):204-208.e1.

13. Sun $X, X u X$, Zhang X. Counterfeit bevacizumab and endophthalmitis. N Engl J Med. 2011;365(4):378-379.

14. Lee SH, Woo SJ, Park KH, et al. Serratia marcescens endophthalmitis associated with intravitreal injections of bevacizumab. Eye. 2010;24(2): 226-232.

15. Ryan MP, Pembroke JT, Adley CC. Ralstonia pickettii: a persistent gram-negative nosocomial infectious organism. J Hosp Infect. 2006;62(3):278-284.

16. Riley PS, Weaver RE. Recognition of Pseudomonas pickettii in the clinical laboratory: biochemical characterization of 62 strains. J Clin Microbiol. 1975;1:61-64.

17. Roberts LA, Collignon PJ, Cramp VB, et al. An Australia-wide epidemic of Pseudomonas pickettii bacteraemia due to contaminated "sterile" water for injection. Med J Aust. 1990;152:652-655.
18. Chetoui H, Melin P, Struelens MJ, et al. Comparison of biotyping, ribotyping, and pulsed-field gel electrophoresis for investigation of a common-source outbreak of Burkholderia pickettii bacteremia. J Clin Microbiol. 1997;35:1398-1403.

19. Moreira BM, Leobons MB, Pellegrino FL, et al. Ralstonia pickettii and Burkholderia cepacia complex bloodstream infections related to infusion of contaminated water for injection. J Hosp Infect. 2005;60:51-55.

20. McNeil MM, Solomon SL, Anderson RL, et al. Nosocomial Pseudomonas pickettii colonization associated with a contaminated respiratory therapy solution in a special care nursery. J Clin Microbiol. 1985;22:903-907.

21. Anderson RL, Bland LA, Favero MS, et al. Factors associated with Pseudomonas pickettii intrinsic contamination of commercial respiratory therapy solutions marketed as sterile. Appl Environ Microbiol. 1985;50:1343-1348.

22. Verschraegen G, Claeys G, Meeus G, et al. Pseudomonas pickettii as a cause of pseudobacteremia. J Clin Microbiol. 1985;21:278-279.

23. Oie S, Kamiya A. Bacterial contamination of commercially available ethacridine lactate (acrinol) products. J Hosp Infect. 1996;34: 515-518.

24. Girlich D, Naas T, Nordmann P. OXA-60, a chromosomal, inducible, and imipenem-hydrolyzing class D beta-lactamase from Ralstonia pickettii. Antimicrob Agents Chemother. 2004;48(11):4217-4225.

25. Joseph CR, Lalitha P, Sivaraman KR, Ramasamy K, Behera UC. Realtime polymerase chain reaction in the diagnosis of acute postoperative endophthalmitis. Am J Ophthalmol. 2012;153(6):1031-1037.e2.
Clinical Ophthalmology

\section{Publish your work in this journal}

Clinical Ophthalmology is an international, peer-reviewed journal covering all subspecialties within ophthalmology. Key topics include: Optometry; Visual science; Pharmacology and drug therapy in eye diseases; Basic Sciences; Primary and Secondary eye care; Patient Safety and Quality of Care Improvements. This journal is indexed on

\section{Dovepress}

PubMed Central and CAS, and is the official journal of The Society of Clinical Ophthalmology (SCO). The manuscript management system is completely online and includes a very quick and fair peer-review system, which is all easy to use. Visit http://www.dovepress.com/ testimonials.php to read real quotes from published authors. 